\title{
A DESTERRITORIALIZAÇÃO EM OS PASSOS PERDIDOS DE ALEJO CARPENTIER
}

Márcia Benedita Barbieri*

\section{RESUMO}

O objeto desse estudo são as aproximações, as ressonâncias entre as obras "Os passos perdidos" de Alejo Carpentier e o projeto filosófico de Gilles Deleuze e Félix Guattari. Nosso objetivo não será encontrar pontos de influência, mas movimentos de deslocamento, linhas de fuga, desterritorializações que percorrem a obra carpentiana em questão. Tentamos compreender como essas desterritorializações atravessam a escritura de "Os passos perdidos".

Palavras-chaves: Filosofia. Literatura. Desterritorialização

\section{INTRODUÇÂO}

Durante toda sua obra filosófica Gilles Deleuze imprime grande importância às manifestações artísticas. Em Diferença e repetição considera que o conceito filosófico de repetição pode ser encontrado na linguagem poética, tal linguagem trabalha com a repetição singular, onde cada termo mostra-se insubstituível: "Pius Servien distinguia, com justeza, duas linguagens: a linguagem das ciências, dominada pelo símbolo da igualdade, onde cada termo pode ser substituído por outros, e a linguagem lírica, em que cada termo, insubstituível, só pode ser repetido." (DELEUZE, p. 22, 1988). Em Diálogos dedica grande parte do livro aos conceitos de desterritorialização e de devir, discutindo as maneiras pelas quais esses conceitos estão presentes em algumas obras literárias, por exemplo, em Moby Dick de Melville, em Trópico de Capricórnio de Miller: "A literatura angloamericana apresenta continuamente

\footnotetext{
* Universidade Federal Paulista - UNIFESP, mestranda do curso de Filosofia, marcia barbieri@hotmail.com
} 
rupturas, personagens que criam sua linha de fuga, que criam por linha de fuga. Thomas Hardy, Melville, Stevenson, Virginia Woolf, Thomas Wolfe..." (Deleuze e Parnet, 1998, p.30)

Ele apropria-se da literatura para criar, deslocar ou inventar conceitos filosóficos. A literatura não é acionada como um mero instrumento para exemplificar esses conceitos, tampouco justificá-los ou legitimá-los. Porém, ele deixa claro que a filosofia não pode criar afectos e a literatura não pode criar conceitos, cabe à filosofia criar conceitos: "As duas tentativas recentes para aproximar a arte da filosofia são a arte abstrata e a arte conceitual; mas não substituem o conceito pela sensação, criam sensações e não conceitos." (DELEUZE e GUATTARI, 1992, p. 233).

Deleuze distingue diferentes formas de criação entre os vários saberes. Enquanto a literatura trabalha com afectos e perceptos, a ciência com funções, a filosofia trabalha com a criação de conceitos. Não há, portanto, privilégios de uma área sobre as outras, tanto a ciência quanto a arte ou a filosofia são criadoras, cada qual a sua maneira. O objetivo da ciência é criar funções, o da arte é criar agregados sensíveis e o objetivo da filosofia é criar conceitos: “A filosofia faz surgir acontecimentos com seus conceitos, a arte ergue monumentos com suas sensações, a ciência constrói estados de coisas com suas funções." (DELEUZE e GUATTARI, 1992, p. 234). No entanto, quando Deleuze aciona outros domínios, como a expressão literária, seu intuito é estabelecer conexões, ressonâncias. Deslocar tanto a literatura quanto a filosofia, pois o importante é uma filosofia movente e criadora. Assim, um agregado sensível vindo da literatura pode estimular a criação de um conceito ou um conceito filosófico pode mover um bloco de afectos e perceptos. Há entre as três áreas de pensamento um cruzamento, que faz surgir o pensamento como heterogênese. Ou seja, a sensação pode tornar-se sensação de conceito ou de função, o conceito pode tornar-se conceito de função ou sensação, a função, função de sensação ou conceito.

Assim, Deleuze mostra que a literatura existe como algo não delimitado, com constantes rupturas e linhas de fuga: "Se há progressão em arte, é porque a arte só pode viver criando novos perceptos e novos afectos como desvios, retornos, linhas de partilha, mudanças de níveis e escalas..." (DELEUZE e GUATTARI, 1992, p.228).

Para o filósofo os personagens não são sujeitos, mas blocos de sensações, individuação sem sujeito, os personagens são intensidades, afetos, potências. A escrita é um processo interminável, escrever é devir, é encontrar a zona de vizinhança entre dois reinos. A literatura só pode começar com a morte do eu e com a descoberta do impessoal. Por isso, a identidade do escritor é tão insignificante, o escritor é o impessoal, o it, é o corpo sem órgãos, aquele que 
está a serviço do pensamento que pensa e cria o novo, da violência dos encontros, dos incorporais, das intensidades, aquele que consegue traçar as linhas de fuga. $O$ escritor pode se valer de um plano inicial de organização, mas é apenas através do plano de composição que a obra nasce, a obra nasce nas linhas de fuga, todo o resto é tentativa, preenchimento de lacunas. A obra de arte se quer corpo pleno sem órgãos, anarquia coroada, toda obra tem ojeriza aos órgãos, aos saberes instituídos, não é por acaso que a primeira pessoa a renegar os órgãos tenha sido um artista. Anne Sauvagnargues, em sua interpretação sobre o corpo sem órgãos e sua relação com a arte, afirma:

Deleuze assinala na arte a tarefa de dar acesso a essa corporeidade antes da organização, ou seja, de captar a vida antes que ela se estabilize em organismos diferenciados. Parece então, que a arte se coloca na origem do processo de diferenciação, antes que o fluxo vital se fixe em uma forma orgânica. ${ }^{1}$

A literatura está o tempo todo por fazer, não existe um texto finalizado, a escrita não acaba quando termina uma obra, ela atravessa o vivível e o vivido, por isso, nenhuma obra pode ser explicada através do sujeito, ela independe do sujeito, a escrita está em eterno devir: “Escrever é um caso de devir, sempre inacabado, sempre em via de fazer-se, e que extravasa qualquer matéria vivível ou vivida. É um processo, ou seja, uma passagem de Vida que atravessa o vivível e o vivido." (DELEUZE, 1997, p. 11)

Nesta pesquisa, nossa intenção é expor os pontos de convergência entre o livro Os passos perdidos de Alejo Carpentier e o conceito filosófico de desterritorialização de Gilles Deleuze. Veremos como o deslocamento será importante para que o narrador de Os passos perdidos comece uma desterritorialização, a qual passará pelo desejo de desorganizar o próprio corpo e atravessará toda a estrutura narrativa.

A obra de Carpentier é uma escritura em constantes linhas de fuga. Uma escritura que se recusa uma classificação reducionista na teoria dos gêneros. Uma escritura que nos convida a seguir seus rastros, não em linha reta, mas nas suas ramificações, nos seus rizomas. Perceber o processo de construção dessas linhas de fuga nos fez suspeitar de uma aproximação do projeto filosófico de Deleuze e Guattari. Um encontro entre o escritor que desterritorializa afectos e perceptos e os filósofos que desterritorializam conceitos. Conceitos como

\footnotetext{
${ }^{1}$ Deleuze et l'art. Anne Sauvagnargues. p. 90
} 
desterritorialização, rostidade, $\mathrm{CsO}$, literatura menor participam tanto de uma filosofia produtora de diferenças como também se mostraram pertinentes para uma leitura de Os passos perdidos.

O conceito de desterritorialização é essencial para o trabalho e tornou-se nosso eixo principal. Tornou-se uma forma de aproximar Carpentier, Deleuze e Guattari.

O processo metodológico que escolhemos, ou seja, a criação de um bloco de ressonância entre o texto literário e a filosófico exigiu alguns cuidados para evitar que nos precipitássemos em um reducionismo ou hierarquização, no qual um campo sugerisse respostas ao outro. Nossa leitura tenta criar pontos de ressonâncias duplos, ou seja, esperamos que os conceitos deleuze-guattarianos nos auxiliem a percorrer Os passos perdidos, mas que Os passos perdidos também consigam deslocar os conceitos de Deleuze e Guattari.

Nossa leitura do livro seguirá um conselho do próprio Deleuze em Conversações:

(...) consideramos um livro como uma pequena máquina asignificante, o único problema é: isso funciona, e como é que funciona? Como isso funciona para você? Se não funciona, se nada passa, pegue outro livro. Essa outra leitura é uma leitura de intensidades: algo passa ou não passa. Não há nada a explicar, nada a compreender, nada a interpretar. (1992, p. 16)

Desse modo tentamos percorrer as linhas da obra de Carpentier e sentir como funciona essa máquina literária.

Faremos uma breve apresentação do autor e da obra literária em questão.

Alejo Carpentier nasceu em Cuba e passou a infância em Havana. Ele era filho de um francês e de uma russa. Carpentier foi diretor da Revista Carteles entre 1924 e 1928. Colaborou na fundação da Revista de Avance em 1927. Em 1928 foi exilado durante a ditadura de Machado, regressando a Cuba depois de mais de uma década. Nesse período escreveu sua primeira obra literária Ecué-Yamba-O (publicada em 1933), um romance de temática negra. Em 1944 mudou-se para Caracas, dedicando-se à rádio e à vida acadêmica, nesse período foi colunista em jornais e revistas diversas, divulgando a música contemporânea. Regressou à Cuba depois da Revolução e ocupou vários cargos oficiais, em 1966 foi embaixador em Paris. Em 1944 lançou uma coletânea de contos intitulada Viagem à semente. Em 1946 publicou um ensaio $A$ música em Cuba. Em 1949 publicou um dos seus trabalhos mais emblemáticos 0 
reino deste mundo. Em 1953 é definitivamente consagrado com a obra Os passos perdidos. Escreve, depois dessa obra de indiscutível expressão, outros grandes romances.

$\mathrm{Na}$ obra Os passos perdidos, o autor utiliza parágrafos extensos, criando assim um ritmo na leitura e permitindo que o leitor seja conduzido pela história. A linguagem é formal e de uma musicalidade inigualável, revelando o músico por trás do autor.

O livro narra a história de um musicólogo cujo nome não é exposto. A história gira em torno de sua vida vazia e sem motivação na cidade de Nova lorque. O protagonista é casado com a frustrada atriz Ruth. A vida do casal estava desgastada, a convivência torna-se cada vez menor e muitas vezes eles ficavam juntos apenas por supostas "obrigações" conjugais e não por um desejo real.

A vida do musicólogo começa a mudar quando sua esposa é convidada para uma viagem inesperada para encenar uma peça, tal viagem ocorre ao mesmo tempo em que o narrador entra em férias. Ao encontrar-se sozinho o protagonista começa a andar sem rumo, recorda da inutilidade do seu emprego, no qual precisa utilizar a música, sua maior paixão, de forma mecanizada, recorda da frieza do seu relacionamento com a esposa.

Em uma de suas saídas sem rumo, o musicólogo entra em um concerto sinfônico, ao terminar o concerto, ele encontra o Curador do Museu Organográfico, que o convida para uma viagem pela América Latina com o intuito de procurar instrumentos primitivos, mesmo o protagonista revelando o vazio e a improdutividade em que se encontrava e na inutilidade que via em tal empenho.

O protagonista foge da casa do Curador e vai para um bar próximo, onde encontra Mouche, sua amante que passa a ganhar espaço na história a partir desse evento. Ao contar para sua amante o "convite" que recebeu, ela imediatamente se anima e se dispõe a ir com ele para a Venezuela em busca das peças.

O livro passa a relatar as experiências dos dois amantes durante a viagem, o protagonista aos poucos vai se interessando pelas singularidades dos lugares que conhece. A viagem se transforma em um esquadrinhamento da identidade dos personagens e na retomada de etapas da história da América do Sul.

À medida que a viagem se desenrola, ele se vê cada vez mais envolvido-afetado pelo "mundo novo". Nesse convívio com a selva e com civilizações que ainda não foram totalmente capturadas pelos poderes instituídos no mundo ocidental como o Estado, a burocracia e o 
capital financeiro, sua vida se modifica, ele começa a reorganizar suas crenças, seus objetivos, sua vida amorosa e sua carreira. A sua busca deixa de ser apenas pelos objetos primitivos, passa a ser também uma busca pela cultura, pela história daquele povo e uma reflexão sobre sua própria vida.

A viagem continua e em uma das pousadas onde o casal se hospeda, um homem que chega ao povoado confunde Mouche com uma prostituta e tenta agarrá-la. Começa então uma briga e uma mulher chamada Rosário vem para acalmar os dois homens.

A partir desse momento o protagonista fica confuso, pois Mouche apesar da briga faz insinuações para o outro homem, Rosário se aproxima cada vez mais do musicólogo. Ele se arrepende por ter levado a amante na viagem, pois gostaria de se misturar mais com a tripulação do ônibus em que viaja, principalmente com Rosário.

A busca pelos itens primitivos e por sua identidade continua, novos lugares e culturas são descobertas. O musicólogo redescobre o prazer de compor em meio à vida primitiva e em companhia da nova amante Rosário. No entanto, ele é dado como desaparecido e uma equipe vem resgatá-lo da selva, assim ele acaba retornando para sua casa em Nova lorque.

Ele se encontra em uma situação complicada, pois Ruth voltou de viagem disposta a interpretar o papel de esposa e ele sente-se preso ao amor primitivo de Rosário. 0 protagonista resolve contar tudo a sua esposa e pedir o divórcio.

Ele retorna à selva para procurar Rosário, no entanto, ela já está sobre a proteção de outro homem. O protagonista percebe que seus mundos são muito diferentes e que ele não poderá ser feliz morando na selva, pois ele depende da arte e a arte não tem sentido para o mundo selvagem em que Rosário se encontra.

Antes de compreendermos como funciona a máquina literária de Os passos perdidos, entendemos ser necessário um aprofundamento nos conceitos deleuze-guattarianos como 0 corpo sem órgãos, por exemplo.

\section{Corpos sem órgãos}

Deleuze e Guattari afirmam que temos um ou mais de um Corpo sem Órgãos, ele não é inteiramente dado, é necessário fazê-lo, produzi-lo e toda vez que desejamos estamos a caminho da feitura desse corpo: “De todo modo você tem um (ou vários), não porque ele pré- 
exista ou seja dado inteiramente feito - se bem que sob certos aspectos ele pré-exista - mas de todo modo você faz um, não pode desejar sem fazê-lo..."2

Os autores advertem-nos que encontrar um Corpo sem Órgãos não é uma tarefa fácil, é uma tarefa extremamente difícil, assustadora, porque podemos falhar nesse empreendimento. Ele é não-desejo e simultaneamente desejo. Não podemos assegurar que se trata de uma noção, de um conceito, ele é um exercício, uma experimentação, um conjunto de práticas. Além disso, criar um Corpo sem Órgãos requer cuidados, caso contrário, pode levar ao nosso aniquilamento: “Não é tranquilizador porque você pode falhar. Ou às vezes pode ser aterrorizante, conduzi-lo à morte. Ele é não-desejo, mas também desejo. Não é uma noção, um conceito, mas antes uma prática, um conjunto de práticas." ${ }^{3}$

Em Mil platôs, volume 3, os autores dizem que ao O Corpo sem Órgãos não se chega nunca, porque trata-se de um limite, por isso dizemos que ele não nos é dado, é preciso criá-lo e recriá-lo constantemente, tateá-lo, persegui-lo. A partir do Corpo sem Órgãos descobrimos nossas vitórias e nossas derrotas, nossos desejos, nossos amores: "é sobre ele que dormimos, velamos, que lutamos, lutamos e somos vencidos, que procuramos nosso lugar, que descobrimos nossas felicidades inauditas e nossas quedas fabulosas, que penetramos e somos penetrados, que amamos" ${ }^{4}$.

Poderíamos nos perguntar como conseguimos alcançar o Corpo sem Órgãos. No entanto, dessa forma estaríamos colocando a questão de forma equivocada, pois, como já foi dito, o Corpo sem Órgãos não pode ser encontrado e utilizado, uma vez que ele é uma experimentação, um limite, um conjunto de práticas, ele não se encontra em um lugar determinado, antes é necessário inventá-lo.

Antes de explicarmos melhor como criar um Corpo sem Órgãos, é imprescindível explicar melhor a que nos referimos quando utilizamos o conceito de Corpo sem Órgãos, quando ele surgiu pela primeira vez e como ele foi apropriado pelos filósofos. O que é o Corpo sem Órgãos? Precisamos esclarecer que o Corpo sem Órgãos não se trata de um corpo esvaziado de órgãos, não estamos falando aqui sobre um corpo que não possui coração, pulmões, fígado. Então, do que falamos, realmente?

\footnotetext{
${ }^{2}$ Mil platôs vol. 3, p.11

${ }^{3}$ Idem p.12

${ }^{4}$ Idem p.12
} 
Quem utilizou o conceito pela primeira vez foi o autor francês Antonin Artaud, de acordo com Deleuze e Guattari, Artaud declarou em 28 de novembro de 1947 guerra aos órgãos, segundo Artaud não existe nada mais inútil do que os órgãos, fazendo assim uma alusão à repressão instaurada pelos órgãos. Os órgãos impedem a livre experimentação. Os filósofos seguem essa ideia afirmando: “É uma experimentação não somente radiofônica, mas biológica, política, atraindo sobre si censura e repressão. Corpus e Socius, política e experimentação. Não deixarão você experimentar em seu canto." ${ }^{5}$

No entanto, não devemos confundir o Corpo sem Órgãos com um corpo dilacerado, com um corpo vazio, destituído de órgãos. Para os filósofos o conceito de Corpo sem Órgãos significa um corpo que tem ojeriza pela organização despótica dos órgãos, de como eles atuam, dessa forma, não é contra os órgãos que lutamos, mas contra o organismo, em um corpo deve haver somente campos de intensidades e os órgãos devem funcionar como campos de intensidades

Dessa forma, fica evidente que não estamos afirmando que um CsO é um corpo esfacelado, dilacerado, incompleto, ao contrário, não há nada mais vivo e pulsante do que um CsO, nele só passam intensidades: “Um CsO é feito de tal maneira que ele só pode ser ocupado, povoado por intensidades. Somente as intensidades passam e circulam." ${ }^{\prime 6}$

Já ficou claro que não estamos nos referindo a um corpo esvaziado ou incompleto. Entretanto, surge uma dúvida quanto à realidade dos Corpos sem Órgãos, será que eles são tão reais quanto os outros corpos?

Deleuze e Guattari ajudam-nos com essa dúvida, afinal, estamos falando de um corpo pleno em intensidades e ainda assim um corpo real. Mas devemos atentar que não é uma realidade extensa, quantificável e mensurável como dos outros corpos. O Corpo sem Órgãos é real assim como as partes extensas do mundo que nos rodeia, porém, não se trata de uma realidade extensiva e sim de uma realidade intensiva. Sempre que falamos em Corpo sem Órgãos estamos lidando com um campo de intensidades. O CsO não pode ser definido como um lugar específico ou um suporte em que as coisas ocorrem, antes, ele é um spatium intensivo, onde povoam as intensidades em movimentos constantes. Ou seja, para se transformar em um CsO é preciso fazer com que o corpo seja tomado pelas forças intensivas:

\footnotetext{
${ }^{5}$ Idem p.12

${ }^{6}$ Idem p.16
} 
"Mas o CsO não é uma cena, um lugar, nem mesmo um suporte onde aconteceria algo. Nada a ver com um fantasma a interpretar. O CsO faz passar intensidades, ele as produz e as distribui num spatium ele mesmo intensivo, não extenso." ${ }^{7}$

Por isso, quando nos propomos a criar um CsO não estamos falando de um corpo que não possua órgãos, interpreta erroneamente aquele que imagina que os adversários do CsO sejam os órgãos, o que o CsO não aceita é o despotismo do organismo, que supõe ordens e funções exatas para cada órgão: "Percebemos pouco a pouco que o CsO não é de modo algum contrário dos órgãos. Seus inimigos não são os órgãos. O inimigo é o organismo. O CsO não se opõe aos órgãos, mas a essa organização dos órgãos que se chama organismo." ${ }^{8}$

Assim, afirmamos com Deleuze e Guattari que os corpos sem órgãos podem somente ser criados na presença dos encontros. Não é possível criar um CsO se não aprendermos a desviar o tempo inteiro da estratificação, a estratificação é a condenação do CsO, é necessário fugir das organizações rígidas, essas organizações tentam, a todo custo, nos dizer com propriedade quem nós somos, o que nosso corpo pode, o que devemos e o que não devemos fazer, como devemos agir, como devemos falar, como devemos andar, o que devemos pensar, que leis devemos seguir, quais sensações podem passar pelos nossos corpos. É exatamente isso que o CsO recusa, a organização extrema, a hierarquia coroada: aonde ir, como agir, o que pensar e como sentir:

O organismo já é isto, o juízo de Deus, do qual os médicos se aproveitam e tiram seu poder. O organismo não é o corpo, o CsO, mas um estrato sobre o $\mathrm{CsO}$, quer dizer um fenômeno de acumulação, de coagulação, de sedimentação que lhe impõe formas, funções, ligações, organizações dominantes e hierarquizadas... ${ }^{9}$

Dessa forma, é fácil compreender que não é uma questão de esvaziar o corpo dos órgãos vitais. O empreendimento, a luta não é contra os órgãos, a luta é contra a fixação de um poder, de um sujeito, contra os estratos que nos impedem de caminhar, é contra um juízo de Deus sobre nosso corpo. Afirmamos que a batalha é contra o organismo, a significância, a sujeição e a interpretação.

\footnotetext{
${ }^{7}$ Idem p.16

${ }^{8}$ Idem p.24

${ }^{9}$ Idem, p. 24
} 
Percebemos que o protagonista de Os passos perdidos está mergulhado em um mundo instituído, ele mesmo um corpo automatizado, um corpo plastificado. A luta do personagem ao longo da narrativa é para livrar-se do juízo de Deus, das estratificações, das sedimentações e coagulações que proliferam sobre seu corpo:

\begin{abstract}
"Havia grandes lacunas de semanas a semanas na crônica de meu próprio existir; temporadas que não me deixavam uma lembrança válida, o rastro de uma sensação excepcional, uma emoção duradoura; dias em que todo gesto me produzia a obsedante impressão de tê-lo feito antes em circunstâncias idênticas - de ter sentado no mesmo canto, de ter contado a mesma história, olhando o veleiro preso no cristal de um pesa-papéis." (CARPENTIER, p. 11, 2009)
\end{abstract}

A história Os passos perdidos apresenta-nos personagens encapuzados, que não conseguem livrar-se do quadrado limitado das combinações dadas previamente. Ruth, por exemplo, passa a narrativa toda encenando o mesmo papel, sua vida limita-se ao confinamento em um palco imitando sempre a mesma voz, os mesmos gestos ensaiados, ela não consegue escapar das estratificações, permanece um corpo organizado, longe de entregar-se à possibilidade do encontro:

"Agora chegávamos às mil e quinhentas representações, sem que os personagens, atados por contratos sempre prorrogáveis, tivesse alguma possibilidade de evadir-se da ação, desde que os empresários, passando o generoso empenho juvenil ao plano dos grandes negócios, haviam acolhido a obra em seu consórcio. Assim, para Ruth, longe de ser uma porta aberta sobre o vasto mundo do Drama - um meio de evasão -, esse teatro era a ilha do Diabo." (CARPENTIER, p. 6, 2009)

Ruth não pensa, pois o seu trabalho de atriz aniquilou a sua capacidade de pensar, ela repete infinitas vezes as mesmas falas, os mesmos gestos, os mesmos pigarros em um tempo marcado. As falas do teatro não se alteram, por vezes, pode ocorrer uma improvisação, no entanto, dada a repetição contínua nem as improvisações são necessárias levando o pensamento ao máximo de sua banalidade. Um pensamento acontece apenas diante de um teatro esquizofrênico, em que possibilidades de mundo se abrem através das falas não 
ensaiadas, só um esquizofrênico chega próximo do que é o verdadeiro pensamento, Artaud, por exemplo. Artaud tinha plena consciência de que o pensamento não era inato e jamais pensaria, caso acreditasse no inatismo do pensamento, deveria destruir a ideia de pensamento inato e colocar em seu lugar a ideia do pensamento genital.

Assim como Ruth, o protagonista no início da narrativa também tinha perdido a capacidade de pensar. Um homem preso na mesmice dos dias, em que cada gesto, assim como em uma encenação teatral parece ensaiado, parece já ter sido vivido anteriormente. Como um homem nessas condições poderia engendrar um pensamento, criar a violência necessária para sair do inatismo para o genitalismo?:

Às vezes, também, minha informação sobre o passar das estações devia-se aos sinos de papel vermelho que se abriam nas vitrines das lojas, ou à chegada de caminhões carregados de pinheiros cujo perfume deixava a rua como que transfigurada durante alguns segundos. (CARPENTIER, 2009, p. 11)

Podemos igualmente afirmar que o narrador é um corpo organizado, no entanto, à medida que sai de Nova lorque, começa a se desterritorializar, ele consegue sair de um espaço limitado, de um "quadrilátero" e se abrir em busca do encontro: "Nada do que se oferecia ao olhar era monumental ou insigne; nada havia passado ainda para o cartão postal, nem era elogiado em guias de viajantes." (CARPENTIER, p. 71, 2009)

Já um corpo organizado não está aberto para novas possibilidades, apenas um corpo sem órgãos ou em vias de se tornar um corpo sem órgãos se deixa atravessar por intensidades, se deixa afetar por outros corpos, abrindo assim o caminho que conduzirá a um descentramento, uma dissolução do seu eu, a uma desterritorialização, a uma afetação do corpo:

(...) penso que ainda não me acostumei com a ideia de me achar tão longe de meus caminhos habituais. E ao mesmo tempo há como uma luz recuperada. Um aroma de grama quente, de água do mar que o céu parece penetrar em profundidade, chegando ao mais fundo de seus verdes - e também certa mudança da brisa que traz o fedor de crustáceos podres em alguma sovaca da costa. (CARPENTIER, 2009, p. 44) 
Perguntamo-nos o que pode salvar o corpo de uma letargia, de um esgotamento e de uma paralisação própria dos nossos tempos. O narrador é impulsionado para um modo de vida primitivo quando tenta responder a essa questão:

De súbito, um calor de fogaças mornas, de massa recém-assada, brotou dos respiratouros de um porão, em cuja penumbra labutavam, cantando, vários homens, brancos da cabeça aos pés. Detive-me com deleitosa surpresa. Fazia muito tempo que esquecera essa presença de farinha nas manhãs, lá onde o pão, amassado não se sabia onde, trazido de noite em caminhões fechados, como matéria vergonhosa, tinha deixado de ser o pão que se parte com as mãos..." (CARPENTIER, 2009, p. 52)

Nosso corpo passou por um processo de adestramento que o condicionou à catástrofe, mas não a catástrofe da automutilação, mas a da mansidão. O processo civilizatório condicionou o corpo ao silenciamento, impôs suas próprias regras, aniquilou os instintos. Apenas alguns corpos fizeram do adestramento uma linha de fuga para a criação de um corpo anárquico. A maioria dos corpos permanece organizado, como é o caso da personagem Ruth, que foi dominada pelos aparelhos de Estado.

Um corpo silenciado pela banalidade não pode ser afetado e um corpo só pode ser definido pela sua capacidade de afetação. $O$ corpo não pode ser definido por seus órgãos ou suas funções, um corpo deve ser definido pela sua capacidade de ser afetado, de entrar em conjugações com outros corpos. Um corpo só é válido pelas suas potências, pelos seus afectos, como eles podem afetar ou ser afetados por outros corpos, para destruir ou ser destruído, para provocar paixões. Enfim, um corpo é um calabouço de possibilidades e de relações, um corpo é um maquinário de conexões infinitas.

O narrador não desorganiza seu corpo porque deseja destruí-lo, mas ao contrário, porque deseja revitalizá-lo, potencializá-lo, abri-lo para novas experiências, dissolver o seu eu, ser aspirado, multiplicado, falar como multiplicidade: "Não chegar ao ponto em que não se diz mais EU, mas ao ponto em que já não tem qualquer importância dizer ou não dizer EU." (DELEUZE, p.17, 2011). Essas relações ou afeç̧ões acontecem tanto externamente quanto internamente, levando o narrador para o deslocamento, para o encontro de uma nova subjetividade.

O narrador, em um desejo incontrolável de desorganização assumiu o risco, ele deseja desorganizar esse corpo, ele deseja um organismo caótico, dar um sopro de vida a este corpo, 
porque um corpo sem órgãos não é um corpo vazio, ao contrário, é cheio de vitalidade, já o corpo organizado é um corpo petrificado, está mais próximo de um boneco de cera do que de um corpo humano. O personagem quer instaurar o caos nesse corpo, deixar de ser um corpo em funcionamento perfeito para instituir um corpo sem órgãos. Mas o que seria esse corpo sem órgãos? Qual o papel desse corpo sem órgãos para a desterritorialização desse narrador?

Atentamos para o fato que o corpo sem órgãos não é apenas um corpo biológico, o corpo sem órgãos pode fazer referência a um corpo econômico, social ou político. Assim, também é fácil notar que o corpo do homem não é somente um corpo biológico, mas uma conexão, um mundo instituído também está acoplado ao corpo humano e também controla o organismo do homem. Não é possível criar um corpo sem órgãos sem desorganizar todo um sistema, sem derrubar e arruinar todas as instituições.

\section{Referências}

CARPENTIER, Alejo. Os passos perdidos, São Paulo: Martins Fontes, 2009.

DELEUZE, Gilles. Diferença e repetição. Rio de Janeiro: Ed. Graal, 1988.

Conversações. Rio de Janeiro: Ed. 34, 2000.

. Lógica do sentido. Rio de Janeiro: Perspectiva, 2009.

Crítica e clínica. Rio de Janeiro: Ed. 34, 2011.

DELEUZE, G., GUATTARI, F. Mil platôs: capitalismo e esquizofrenia, vol. 1, vol. 2, vol. 3, vol. 4 e vol. 5. Rio de Janeiro: Editora 34, 2011, 2011, 2012, 2012 e 2012.

. O que é filosofia? Rio e Janeiro: Editora 34, 2010. Kafka por uma literatura menor. São Paulo: 2014.

DELEUZE, G., PARNET, C. Diálogos. São Paulo: Escuta, 1998.

LAPOUJADE, David (org.). A ilha deserta e outros textos. São Paulo: Iluminuras, 2006.

LINS, Daniel. Antonin Artaud: o artesão do corpo sem órgãos. Rio de Janeiro: Relume Dumará, 1999. 
MOCEGA-GONZÁLEZ, Esther P. Alejo Carpentier: estúdios sobre su narrativa. Madrid: Editorial Playor, 1980.

MACHADO, Roberto. Deleuze, a arte e a filosofia. Rio de Janeiro: Zahar, 2009.

MUÑOZ, Ana Maria (org.). Recopilácion de textos sobre Alejo Carpentier. Cuba: Casa de las Américas, 1977.

SAUVAGNARGUES, Anne. Deleuze et l'art. Paris: Puf, 2006.

SILVA, Cíntia Vieria de. Corpo e pensamento: alianças conceituais entre Deleuze e Espinosa. Campinas: Ed. Unicamp, 2013.

SPINOZA, Benedictus de. Ética Belo Horizonte: Autêntica, 2013. 